\title{
Organ Transplantation in the Open-access Era
}

\section{Juan S Danobeitia}

600 Highland Avenue, H5/301, Department of Surgery -Division of Transplantation, University of Wisconsin School of Medicine and Public Health - Madison Hospital \& Clinics, Madison, WI

The field of organ transplantation has evolved significantly since the first report of a successful kidney transplant performed by Joseph Murray at the Peter Bent Brigham Hospital in 1954. However, this relatively rapid evolution has not been without great difficulties and both clinicians and researchers have devoted significant amounts of time, dedication and resources to overcome the barriers that prevented organ transplants from becoming a widely accepted medical therapy. Throughout this process, the field has relied heavily on technological improvement for the refinement of the technical processes involved in each type of transplant. Today, transplantation is entering a new era characterized by a growing interest in novel methods for the treatment of disease that do not necessarily require transferring solid organs between patients. Areas such as islet transplantation, organ preservation, bioengineering of artificial organs, and stem cell therapies, to name a few, constitute magnificent examples of scenarios where the fusion of technology with cell transplantation biology takes place. However, this rapid expansion in research related to transplantation technology and the growing number of centers and investigators dedicated to this field has led to an increasing requirement for proper channels for the dissemination of information.

The Journal of Transplantation Technologies and Research (JTTR) is a new peer reviewed open access journal published by OMICS publishing group aiming at the diffusion of novel and exciting research in all areas of organ and cell transplantation. Articles in this journal are to be published in electronic format and freely accessible to users around the world, placing JTTR in direct competition with top-ranked subscription based journals and providing authors and readers with the numerous benefits of publishing in the open access era. In addition, the digital format will allow readers to explore novel features such as the delivery of published articles instantly to computer or portable devices twenty-four hours a day, listening to audio versions of the published material, translation of published works to over 50 languages using the journal's website and the possibility of sharing their opinion via numerous social networking sites.

In recent years open access publishing has become a valuable resource for authors and readers around the globe. We have witnessed a significant rise in the number of journals that adhere to the definitions drafted at the Bethesda Meeting on Open Access Publishing or the Creative Commons Attribution License (CCAL) which facilitate the distribution of published scientific works free of charge while maintaining high quality standards through careful peer-review and editorial enhancement. These advantages are likely to benefit the scientific (and non-scientific) community overall and will provide added value to researchers working independently or at institutions where the current costs of subscription to non-open access journals have become prohibitive thus limiting widespread access to information.

Like organ transplantation in its early years, open-access holds great promise but remains controversial and is still developing as the leading publishing strategy preferred by authors. However, the gradual improvement in the quality of published work through open-access journals coupled to the mandate by the National Institutes of Health on Public Access Policy and the expanding set of digital tools available to users, are likely to change this paradigm. And just like the field of organ transplantation slowly found a niche as an effective therapeutic option for many patients, I expect JTTR to gradually position itself as a source for high quality manuscripts exploring all areas related to organ transplantation and technological development for years to come. We look forward to receiving your manuscripts and engaging in what will probably become a fructiferous collaboration that can only lead to the advancement of this fascinating field.
Corresponding author: Juan S Danobeitia, 600 Highland Avenue, H5/301, Department of Surgery -Division of Transplantation, University of Wisconsin School of Medicine and Public Health - Madison Hospital \& Clinics, Madison, WI, 53792, E-mail: DANO@surgery.wisc.edu

Received July 20, 2011; Accepted July 26, 2011; Published September 26, 2011

Citation: Danobeitia JS (2011) Organ Transplantation in the Open-access Era. J Transplant Technol Res 1:102e. doi:10.4172/2161-0991.1000102e

Copyright: (c) Danobeitia JS. This is an open-access article distributed under the terms of the Creative Commons Attribution License, which permits unrestricted use, distribution, and reproduction in any medium, provided the original author and source are credited. 